\title{
Быстродействующие вертикально-излучающие лазеры диапазона 1550 нм
}

\author{
А.Ю. Егоров \\ Санкт-Петербургский национальный исследовательский университет информационных технологий, \\ механики и оптики, 197101, Санкт-Петербург, Россия \\ ООО «Коннектор Оптикс», 194292, Санкт-Петербург, Россия
}

DOI 10.34077/RCSP2019-72

Быстродействующие вертикально-излучающие лазеры (ВИЛ) диапазона 1550 нм являются привлекательным вариантом источника когерентного излучения для реализации различных устройств радиофотоники. К сожалению, монолитные гетероструктуры ВИЛ с инжекцией носителей через легированные распределенные брэгговские отражатели (РБО) сформированные из $\mathrm{AlGaAs} / \mathrm{GaAs}$ и активной областью на основе квантовых ям InGaAs, хорошо зарекомендовавшая себя при создании ВИЛ ближнего ИК-диапазона [1], оказываются непригодны для создания ВИЛ диапазона 1550 нм ввиду невозможности достижения эффективной электролюминесценции на данной длине волны. Применение выращенной в едином эпитаксиальном процессе монолитной гетероструктуры ВИЛ с РБО из InAlGaAsP/InP и квантовыми ямами из InAlGaAs c инжекцией носителей через внутрирезонаторные контактные слои позволяет реализовать ВИЛ диапазона 1550 нм, но не обеспечивает хорошей температурной стабильности характеристик, а эффективная частота модуляции таких приборов ограничена на уровне 4-5 ГГц, что обусловлено малым контрастом показателей преломления и низкой теплопроводностью слоев тройных и четверных твердых растворов в РБО, согласованных по параметру решетки с подложкой InP [2].

Решение данной проблемы возможно за счет применения гибридной конструкции ВИЛ с инжекцией носителей через внутрирезонаторные контактные слои в сочетании с зеркалами на основе диэлектрических материалов. Применения конструкции с двумя внутрирезонаторными контактными слоями и диэлектрическими РБО позволило повысить частоту эффективной модуляции ВИЛ до 21 ГГц и продемонстрировать безошибочную передачи данных на скорости 50 Гбит/с при температуре $20^{\circ} \mathrm{C}$ [3]. Однако такая технология изготовления ВИЛ весьма сложна и требует умения создания высококачественных диэлектрических зеркал.

Альтернативным подходом является использование технологии спекания пластин гетероструктуры активной области на основе нескольких $\mathrm{In}(\mathrm{Al}) \mathrm{GaAs}$ квантовых ям, выращенной на подожке InP, и двух гетероструктур AlGaAs/GaAs РБО, выращенных на подожках GaAs [4]. Изготовленные по такой технологии ВИЛ спектрального диапазона 1.5 мкм демонстрируют частоту эффективной модуляции 7-9 ГГц и безошибочную передачу данных на скорости 10 Гбит/с при температуре $20^{\circ} \mathrm{C}[5]$.

Сравнительно недавно с использованием метода спекания пластин нами была продемонстрирована возможность создания эффективных ВИЛ спектрального диапазона 1550 нм на основе тонких сильнонапряженных InGaAs/InAlGaAs КЯ, пригодных для безошибочной передачи данных на скорости не менее 25 Гбит/с при температуре $20^{\circ} \mathrm{C}[6,7]$. В настоящей докладе будут представлены результаты работ по разработке и созданию таких приборов, а также будут представлены результаты анализа влияния времени жизни фотонов оптическом микрорезонаторе на динамические характеристики одномодовых ВИЛ спектрального диапазона 1550 мкм.

Работа выполнена при поддержке Министерства образования и науки РФ, ФЦП «Исследования и разработки по приоритетным направлениям развития научно-технологического комплекса России на 2014-2020 годы», Соглашение о предоставлении субсидии от 26.09.2017 г. № 14.578.21.0253. уникальный идентификатор RFMEFI57817X0253.

\section{Лumepamypa}

[1] D. Bimberg, A. Larsson, A. Joel, Comp. Semicond. 20(7), 34 (2014)

[2] M.-R. Park, O.-K. Kwon, W.-S. Han, K.-H. Lee, S.-J. Park, B.-S. Yoo, IEEE Photon. Technol. Lett. 18, 1717 (2006)

[3] S. Spiga, W. Soenen, A. Andrejew, D. Schoke, X. Yin, J. Bauwelinck, G. Boehm, M. C. Amann, IEEE J. Lightwave Technol. 35(4), 727 (2017)

[4] A. Syrbu, A. Mircea, A. Mereuta, A. Caliman, C.-A. Berseth, G. Suruceanu, V. Iakovlev, M.

Achtenhagen, A. Rudra, E. Kapon, IEEE Photon. Technol. Lett. 16(5), 1230 (2004)

[5] D. Ellafi, V. Iakovlev, A. Sirbu, G. Suruceanu, Z. Mickovic, A. Caliman, A. Mereuta, E. Kapon, Opt.

Express 22(26), 32180 (2014)

[6] IEEE J. Quant. Electron. 53(6), 2400808 (2017)

[7] Письма в ЖТФ 44(1), 59 (2018) 